\title{
Boom deploying decision support study on inland river based on numerical simulation method"
}

\author{
Rong-Chang Chen \\ China Waterborne Transport Research Institute, \\ Beijing, 100088, P. R. China \\ E-mail: chenrongchang@wti.ac.cn \\ www.wti.ac.cn
}

\begin{abstract}
This paper establishes hydrodynamic models for the focused river section by Delft3D model, simulates the oil spill trajectory and the fates by Oilmap model, and establishes a combined application method of hydrodynamic and oil spill simulation model available for the Yangtze River and other inland waters. The oil spill risk characteristics, hydrological and topographical characteristics of river sections are studied according to the cases, the numerical simulations for the booming effect of three potential deploying schemes (including intercepting, closed V shaped and open V shaped) are simulated by means of the numerical method, and the three boom deploying schemes are analyzed in the deploying difficulty, the impact on navigation, booming effects, recovery effects and other aspects. Research results show that despite relatively difficult deploying, the open $\mathrm{V}$ shaped deploying scheme should be recommended for the focused river section.
\end{abstract}

Keywords: Oil spill; Boom; Decision Support.

\section{Introduction}

There were 42 oil spill incidents with spillage of 7 tons and above in the world during the 2010-2015 period,[1] resulting in total leakage of oil pollutants of 33000 tons.

A major oil spill accident would greatly damage water environment and resources due to the particularity of oil pollution. Inland waters are relatively vulnerable in ecology and most are used for drinking water sources, so compared with the sea waters, inland waters are far heavily affected by oil spill incidents in the damages to ecological environment and negative social impacts. For example, the oil spill of thousands of tons from the explosion hazard of the tanker Jiangyou 423 in Qixia, Nanjing, on June 3, 1997, caused heavy losses to the environment. [2]

\footnotetext{
"This paper is based on the relevant achievements in the Study on Integration Technology of Major Marine Oil Spill Emergency Dispatch Command (No. 2012BAC14B07), a national science and technology support program.
} 
By 2015, there were 25360 berths for production in China's inland waterway ports, of which 414 berths were greater than 10,000 DWT. Daily average standard ship flow in the main channel of the Yangtze River in a year is 647.6 ship-times. [3] The risks of oil spill accidents in the Yangtze River, as a golden watercourse, tend to increase with the growing dangerous goods traffic volume. Therefore, the studies on oil spill emergency responses of the Yangtze River and other inland waters, especially boom deploying schemes, are of importance.

\section{Research Methods}

This paper establishes the hydrodynamic model for the focused river section by Delft3D model. Converting the currents outputs into the netCDF or the ASCII format as Oilmap model inputs. Finally, the oil spill trajectory and the fates are simulated by Oilmap model, [4] and oil spill emergency response measures are studied. The combined application technology roadmap of the two models is shown in Figure 1.

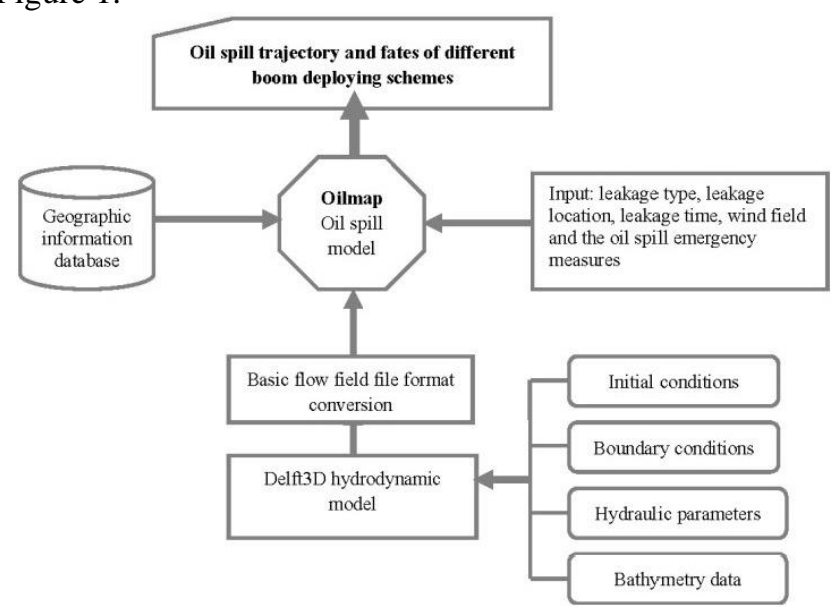

Fig. 1. Combined application technology roadmap of Delft3D and Oilmap.

Delft3D hydrodynamic model,[5] developed by Holland Hydraulic Research Institute and used in two dimensional or three dimensional hydrodynamic simulation, is one of foreign hydrodynamic models widely adopted in China. Hydrodynamic module Flow in the Delft3D is built on the basis of equation Navier-Stokes, after shallow water simplification, the control equation set under the model coordinate system is discretely solved by the alternating direction method.

Oilmap is an oil spill trajectory and fate model developed by the U.S. Applied Science Associates, Inc.( ASA). Oilmap's trajectory model generalizes 
oil particles with mass from oil leakage, and each oil particle is a corresponding fraction of the total volume of oil leakage. In the drift algorithm of the model, the combined effect of wind force, currents, wave and density flow on oil spill is considered. The transport process is calculated by means of Lagrangian particle tracing method, and the diffusion process is calculated by random walk method. Oilmap's fate model is used for calculating the results of oil spill weathering process. The weathering process includes extension, evaporation, water carrying, emulsification and shoreline adsorption. The calculating process complies with the mass conservation, covering oil spill on the water surface, in water and substrate, in the atmosphere, adsorbed on the shoreline, boomed and cleared by manpower. Since Oilmap model was used in the natural resources damage assessment by McCay Deborah French in 1984,[6] the model has been more used in the oil spill risk assessment, and was used in the simulation verification of Exxon Valdez tanker oil spill incident. [7]

\section{Case Studies}

\subsection{Incident scenes and simulation results analysis}

The scene analysis of an oil spill incident mainly includes the location of oil spill, the type of oil spill, spillage, the weather and water conditions when the incident occurred. Since 2000, a typical oil spill incident along the Yangtze River was the oil spill incident from tanker Huanghe 70 on May 17, 2003, with leakage of diesel about 300 tons. In the case study of the oil spill incident, it is assumed that the oil spill incident came from a tanker, with spillage of 300 tons, occurred in the channel of Changshou section in the Yangtze River.

According to the combined application technology roadmap shown in Figure 1, the above incident scenes are simulated by means of Oilmap model. Currents adopts Delft3D outputs, with different boom deploying schemes in the simulation. The booming effects of the deploying schemes are compared.

From the simulation results, we can see, if the booming measures were not taken, the oil pollutants would have drifted with currents more than 6 kilometers in 3 hours, and polluted waters more than 13 kilometers in 8 hours, as shown in Figure 2 and Figure 3. 


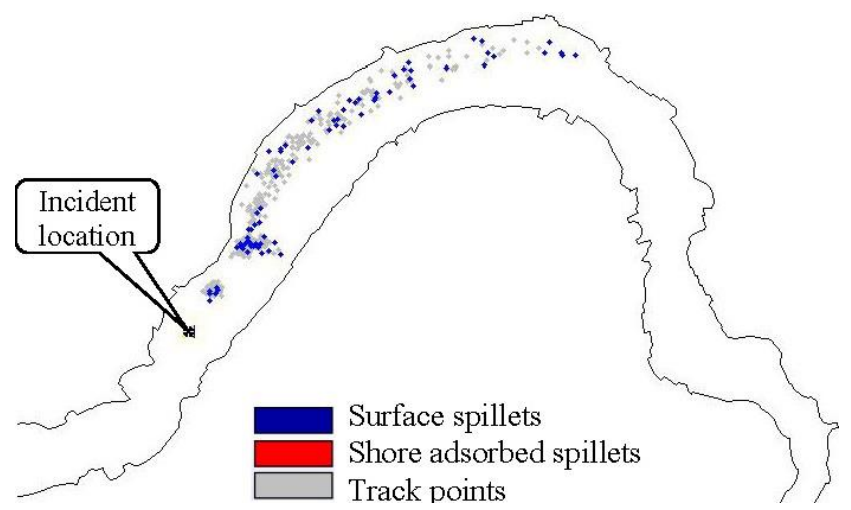

Fig. 2. Oi spill simulation results (3 hours after spill).

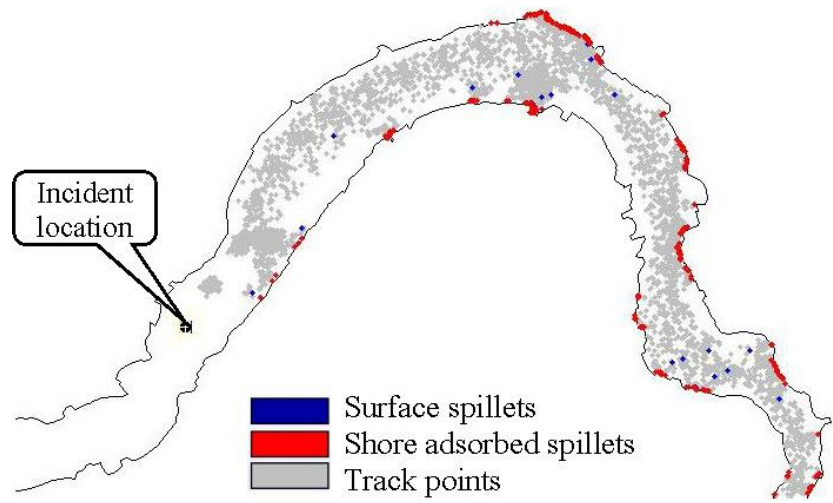

Fig. 3. Oi spill simulation results (12 hours after spill).

\subsection{Influence factors and alternative schemes of boom deploying}

Booms for oil spill are major means and measures for oil spill emergency response in the inland waters. However, boom deploying schemes is very important to the effect of oil spill interception. For deploying booms, local meteorological conditions, hydrology, shorelines and other necessary factors must be considered. The main factors affecting boom deploying schemes include: waters variety, velocity, shoreline types, coastal recovery places for oil spill, water depth, available equipment and human resources, leakage, weather etc.

According to various boom deploying schemes recommended in Oil Spill Response in Fast Currents by the U.S. Coast Guard, [8] the boom deploying schemes include wrapping, dragging, inducing, intercepting and $\mathrm{V}$-shaped deploying methods. The various deploying methods, their applicable situations, merits and demerits are shown in Table 1. 
Table 1. Comparison of conventional boom deploying schemes in inland waters and their merits and demerits.

1 Wrapping $\begin{aligned} & \text { Deploy } \\ & \text { scheme }\end{aligned}$

\subsection{Numerical simulation of various boom deploying schemes}

For the study of the river sections, the width of the river section is about $1 \mathrm{~km}$, the river course within $5 \mathrm{~km}$ scope after the spill location is relatively flat. For the deploying conditions, anchoring in the water, the anchor points on the shore and convenient launching points are necessary. For overall consideration, two ferry places after the incident location are used as the launching points and 
anchoring points of the booms. There are three alternative deploying schemes, i.e., intercepting, closed V shaped and open V shaped. The numerical simulation results of the booming effects are shown in Figure 4-6.

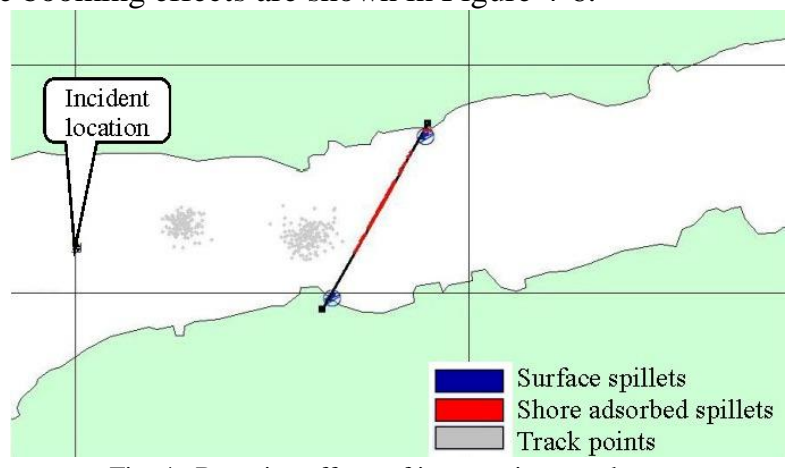

Fig. 4. Booming effects of intercepting type booms

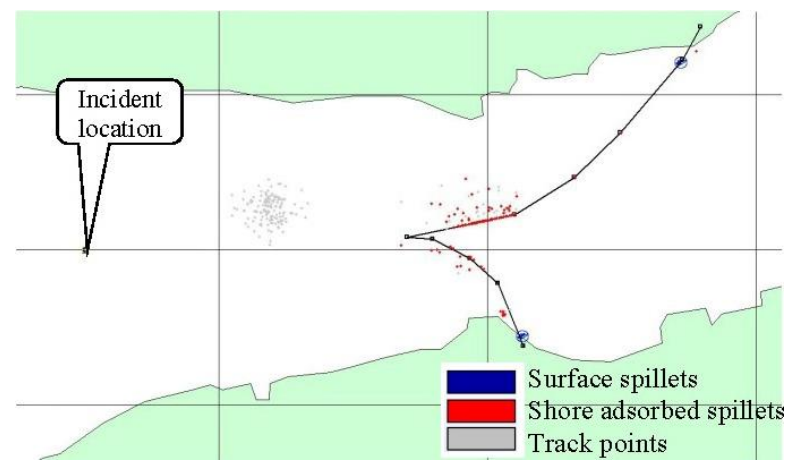

Fig. 5. Booming effects of closed V shaped booms

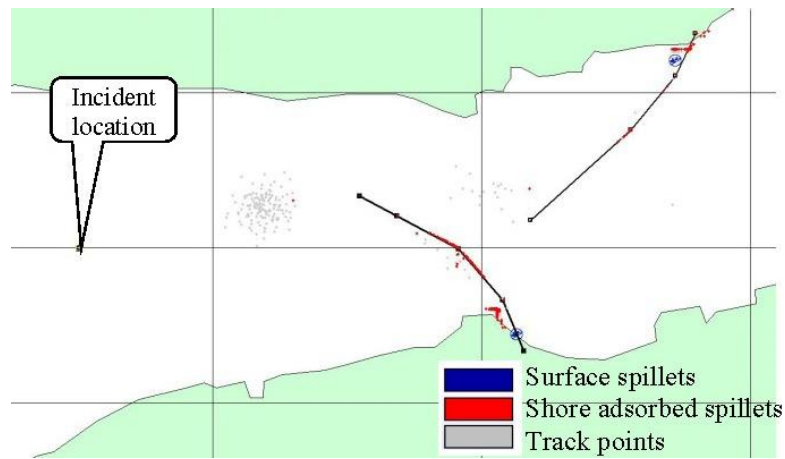

Fig. 6. Booming effects of open $\mathrm{V}$ shaped booms

The three boom deploying schemes are analyzed in the deploying difficulty, the impact on navigation, the booming effects, the recovery effects and other aspects (shown in Table 2). Results show that despite relatively difficult deploying, the open $\mathrm{V}$ shaped deploying scheme should be recommended for the 
focused river section because of no impact on navigation, good booming effects and convenient recovery.

Table 2. Effect comparison of the booming schemes

\begin{tabular}{cccccc}
\hline No. & Scheme & $\begin{array}{c}\text { Deploying } \\
\text { difficulty }\end{array}$ & $\begin{array}{c}\text { Impact on } \\
\text { navigation }\end{array}$ & $\begin{array}{c}\text { Booming } \\
\text { effects }\end{array}$ & $\begin{array}{c}\text { Recovery } \\
\text { effects }\end{array}$ \\
\hline 1 & Intercepting & Low & Non-navigable & Moderate & Poor \\
2 & Closed V-shaped & Moderate & Non-navigable & Moderate & Poor \\
3 & Open V-shaped & Moderate & Navigable & Good & Good \\
\hline
\end{tabular}

\section{Conclusions and Prospects}

This paper establishes hydrodynamic models for river section researches by means of Delft3D, simulates the oil spill trajectory and the fates by means of the Oilmap, and establishes a combined application method of hydrodynamic and oil spill simulation model available for the Yangtze River and other inland waters. The numerical simulations for the booming effect of three potential deploying schemes for the focused river section are performed by the method established. The three boom deploying schemes are analyzed in the deploying difficulty, the impact on navigation, booming effects, recovery effects and other aspects. Results show that the comprehensive effects of the open V-shaped deploying scheme are the best.

The risks of oil spill incidents tend to increase with the growing traffic volume and ships in the Yangtze River and other inland waters, so the studies on oil spill emergency responses are of importance. Due to quick velocity, narrow waters, the difficulties in launching the emergency equipment and anchoring, and other characteristics of inland waters, scientific boom deploying is playing a great role in enhancing the effects of the responses. This paper provides the technical support for the scientific decision of the boom deploying schemes in the emergency response to inland waters oil spill.

\section{References}

1. The International Tanker Owners Pollution Federation Limited, Oil Tanker Spill Statistics 2015(ITOPF, 2016).

http: //www.itopf.com/knowledge-resources/datastatistics/statistics/.

2. J. Hui., Environmental protection in transportation, Vol. 21(2000), pp. 4344.

3. MOT of P.R.C. Traffic and transportation industry development statistics bulletin, 2015 (MOT of P.R.C, Beijing, 2016). http: //zizhan.mot.gov.cn/zfxxgk/bnssj/zhghs/201605/ t20160506_2024006.html. 
4. R.C. Chen, Q. Zhao and J. Deng., China Water Transport, Vol. 11(2011), pp. 65-67.

5. W|L delft hydraulics., Delft3D-FLOW User Manual (W|L, Delft, 2007).

6. M.D. French., Marine Pollution Bulletin, Vol. 47(2003), pp. 341-359.

7. M.D. French., Environmental Toxicology and Chemistry, Vol. 23(2004), pp. 2441-2456.

8. K. Hansen, T.J. Coe., Oil Spill Response in Fast Currents - A Field Guide (U.S. Coast Guard Research \& Development Center, Groton, 2001). 